\title{
EFFECTIVENESS OF HIGH INTEREST RATE POLICY ON EXCHANGE RATES: A REEXAMINATION OF THE ASIAN FINANCIAL CRISIS
}

\author{
TIM BRAILSFORD, JACK H. W. PENM, AND CHIN DIEW LAI
}

Received 25 December 2005; Revised 29 June 2006; Accepted 30 June 2006

One of the most controversial issues in the aftermath of the Asian financial crisis has been the appropriate response of monetary policy to a sharp decline in the value of some currencies. In this paper, we empirically examine the effects on Asian exchange rates of sharply higher interest rates during the Asian financial crisis. Taking account of the currency contagion effect, our results indicate that sharply higher interest rates helped to support the exchange rates of South Korea, the Philippines, and Thailand. For Malaysia, no significant causal relation is found from the rate of interest to exchange rates, as the authorities in Malaysia did not actively adopt a high interest rate policy to defend the currency.

Copyright (C) 2006 Tim Brailsford et al. This is an open access article distributed under the Creative Commons Attribution License, which permits unrestricted use, distribution, and reproduction in any medium, provided the original work is properly cited.

\section{Introduction}

Many countries at the centre of the Asian financial crisis adopted a high interest rate policy in an attempt to defend their currencies. This action is consistent with the traditional view in which tight monetary policy is believed to be necessary for supporting a currency, as higher interest rates increase the return for investing in a country and hence reduce capital outflows, and discourage speculative attacks on the currency concerned.

However, many economists have argued a revisionist view. They believe that when balance of payment crises occur simultaneously with financial crises, as is the case of the Asian financial crisis, a tightening of monetary policy may be counter productive. This is because, they argue, sharply higher interest rates will adversely affect economic activity and financial market confidence. Consequently, such a policy response will lead to further currency depreciation such as Feldstein [6].

Empirical testing of this issue has so far yielded mixed results. Most of the previous studies are not supportive of the use of sharply higher interest rates to defend the currency during financial crises. However, these studies also do not produce findings that support

Hindawi Publishing Corporation

Journal of Applied Mathematics and Decision Sciences

Volume 2006, Article ID 35752, Pages 1-9

DOI 10.1155/JAMDS/2006/35752 
the revisionist view. Many studies fail to identify any significant relationship between interest and exchange rates in the crisis-affected countries.

Recently, Dekle et al. [4] have provided results that empirically support the traditional view. For South Korea, Malaysia, and Thailand, their results indicate changes in interest rates "Granger cause" movements in their respective exchange rates during the Asian financial crisis. Dekle et al. adopt the approach introduced by Hsiao [10] in which a parsimonious vector autoregressive (VAR) specification is determined that allows the presence of zero and nonzero patterned coefficients. The presence of zero and nonzero patterned coefficients appears to have significantly contributed to their findings.

Although Hsiao's approach allows the presence of zero and nonzero patterned coefficients in a VAR system, the model specification is determined by applying an order selection algorithm to each single equation separately, rather than to the system as a whole. As demonstrated by Penm and Terrell [15], the so-determined specification can lead to misleading conclusions on the presence of Granger causality in the system. To overcome this shortfall, Penm and Terrell [15] provide a robust algorithm to select the optimal VAR specification with zero and nonzero patterned coefficients (if the underlying system has such a structure). Brailsford et al. [1] develop an adjustment to this algorithm, which ensures that the resultant variance-covariance matrix of the white noise disturbance process is symmetric for the determined VAR.

In this paper, we reexamine the existence of Granger causality from interest to exchange rates for four Asian countries that were at the centre of the Asian financial crisis, namely Thailand, Malaysia, the Philippines, and South Korea. We apply the algorithm developed by Brailsford et al. [1] to daily observations during the crisis period. An innovative approach that has been adopted in this study is that the relationship is examined allowing for the presence of contagion effects from movements in other crisis-affected Asian currencies. The presence of contagion effects during the Asian financial crisis has been well documented (e.g., Nagayasu [13]). Given the strong contagion effect during the Asian financial crisis, misleading results can be obtained if such an effect is not accounted for in the model.

This paper is organised as follows. In Section 2, brief reviews of the previous studies and interest and exchange rate movements during the Asian financial crisis are presented. Due to the nature of this study, the literature review is limited to those that focus on the testing of Granger causality. In Section 3, we discuss the VAR specifications determined by the procedure developed by Brailsford et al. [1]. We also employ the method presented by Geweke [7] to measure the linear dependence in the systems. Out-of-sample forecasting is then undertaken using the determined VAR models. These results are presented in Section 4, and a summary is given in Section 5.

\section{Previous empirical evidence}

The nature of the interest and exchange rate relationships in the Asian financial crisis has been subjected to a significant debate among international organisations and researchers. For example, the International Monetary Fund argues that sharp rises in interest rates are helpful in stabilising Asian exchange rates (IMF [11]). On the other hand, the World 
Bank believes that significantly higher interest rates destabilised the Asian currencies by markedly increasing the risks of business bankruptcy and economic contraction (Caporale et al. [2]).

Numerous studies have employed Granger causality testing to investigate whether sharply higher interest rates supported or weakened Asian exchange rates during the Asian financial crisis. These studies present mixed results about the effectiveness of using sharply higher interest rates to support Asian exchange rates. Based on the full-order VAR techniques, Goldfajn and Baig [8] estimate the relationship between interest and exchange rate data for a number of Asian countries and find little evidence supporting the use of higher interest rates. Similarly, Kaminsky and Schmukler [12] estimate full-order VAR models using daily nominal interest and exchange rates to calculate the corresponding impulse response functions. Their results also indicate little interaction between interest and exchange rates in either direction. Using full-order VARs in levels, Choi and Park [3] reexamine this issue. They include spot and forward exchange rates and interest rate differentials in their study and conclude that no causal relationship from interest rate differentials to spot exchange rates exists for the countries they investigate.

Attempts have also been made to examine this issue using error correction modelling techniques. For example, Gould and Kamin [9] estimate, in the VECM framework, the relationship between the real exchange rate and domestic interest rates for a number of Asian countries and Mexico. They also include international credit spreads and domestic stock prices, as proxies for creditworthiness and country specific risk, in order to improve the estimation. However, changes in domestic interest rates are still found to be insignificant in influencing movements in the exchange rates.

Notwithstanding the above results, Park et al. [14] use daily observations to test for causal relations between interest and exchange rates in South Korea. They report evidence of Granger causality from higher interest rates to exchange rate movements during the crisis period. As discussed above, Dekle et al. [4] report similar results. Using weekly observations, higher interest rates are found in Granger cause movements in the exchange rates of a number of Asian countries, including South Korea, Thailand, and Malaysia.

Interest and exchange rate movements during the crisis. The Asian financial crisis started in Thailand in mid-1997, with the Thai baht under significant pressure due to speculative currency attacks. The initial responses from the Thai government were intervention in the foreign exchange market and introduction of capital controls. Following a significant worsening of the foreign reserve position, the baht was floated in early July 1997. As these measures failed to stem the sharp decline in the value of the baht, the Thai government sought assistance from the IMF in early August 1997. After an agreement was reached with the IMF, interest rates in Thailand were raised sharply and kept relatively high for the remainder of 1997 and early 1998. Toward mid-1998, interest rates were gradually reduced, following a gradual return of stability in the currency market.

Following the speculative attacks on Thailand's currency, Malaysia's ringgit and the Philippines'peso were also under significant downward pressure as a result of the contagion effect. In Malaysia, the initial response from the government was a sharp increase in the official interest rate. However, this increase lasted only for a short while before interest rates were reduced to the preshock level. Because of a relatively sound foreign reserve 
position, Malaysia did not seek assistance from the IMF and interest rates in that country remained relatively stable.

At the beginning of the Asian financial crisis, the overnight interest rate differential between the Philippines and the United States was the widest in the region. Significant downward pressure on the peso emerged in August 1997. Domestic interest rates in the Philippines became unstable in the second half of 1997. For example, in early October 1997, the overnight interbank call rate increased from around 12 per cent to 102 per cent within a few days, before falling back to the preshock level in late October. In early 1998, the peso exhibited some stability against the US dollar. Consequently, movements in domestic interest rates became less volatile.

Korea's currency, the won, depreciated gradually between July and September 1997, partly reflecting the contagion effect of the currency instability in South-East Asia. The overnight interest rate differential with the United States also gradually widened over this period. Between late October and early December 1997, a crisis of debt financing in Korea emerged, leading to significant downward pressure on the Korean won. In response, domestic interest rates were raised significantly. The Korean government also sought assistance from the IMF in early December 1997.

In the first few months of 1998, the Korean exchange rate was volatile and so was the overnight call rate. A solution emerged, after an agreement was reached with foreign banks to roll over most of Korea's short-term debts, with stability gradually returning to the foreign exchange market.

\section{Empirical test results}

In this section, we present the empirical results of testing for Granger causality between interest and exchange rates for the above-mentioned four Asian countries. Since the debate has focused on the effectiveness of using higher interest rates to defend a sharp decline in currency, we have therefore concentrated this testing over the Asian financial crisis period (defined as from 1 July 1997 to 1 July 1998).

For ease of comparison with previous studies, we have adopted a similar model to Dekle et al. [4], which includes the variables, daily overnight interest rate differential with the United States, exchange rate against the US dollar, and producer price differential with the United States (approximated by the monthly index movements). To capture the currency contagion effect during the crisis period, we also include the exchange rate of the Malaysian ringgit against the US dollar in the models for Thailand, the Philippines, and South Korea. In the case of Malaysia, the Thai baht against the US dollar is used as a proxy.

In the calculation of interest rate differentials, we use the overnight interbank rates for the Asian countries and the daily repo rate for the United States. Following Dekle et al. [4], we employ observations over the whole crisis period. Data of interest and exchange rates were obtained from Datastream. Producer price indexes were from International Financial Statistics.

To undertake this testing, a pretest strategy is followed by first examining for the presence of unit roots and also, where applicable, for cointegration in the models. Based on the ADF test (Dickey and Fuller [5]), all the exchange rates over the crisis period can be 
characterised as integrated of order 1 . While the series of overnight interest rate differential for South Korea is found integrated of order 1, those for Thailand, Malaysia, and the Philippines are stationary. The producer price differentials are also found to be stationary. The hypothesis of cointegration is rejected for each individual system using the Stock and Watson [16] test.

The zero and nonzero patterned VAR specifications are determined using the algorithm developed by Brailsford et al. [1] (together with the Schwarz criterion). No discussion is given on this procedure for the reason of brevity. Interested readers are referred to Brailsford et al. [1] and Penm and Terrell [15] for details.

The estimation results based on the Zellner [17] SUR are presented in Table 3.1. We also apply the Brailsford et al. procedure to the estimated residuals to ensure that they can be characterised as white noise.

As demonstrated by the determined VAR specifications (see Table 3.1), changes in overnight interest rate differentials are found to have affected the exchange rates of Thailand, the Philippines, and South Korea during the Asian financial crisis. For Malaysia, however, the determined zero and nonzero patterned VAR specification indicates that the variable, overnight interest rate differential, is independent of the rest of the system. Consequently, we omit this variable from the system and present the estimation results for Malaysia without this variable.

This finding for Malaysia suggests that over the Asian financial crisis period, interest rate movements in that country do not significantly influence movements in the Malaysian ringgit against the US dollar. This is in contrast to the finding of Dekle et al. [4], but consistent with a priori expectations, as the Malaysian government did not actively adopt a high interest rate policy to defend its currency during the Asian financial crisis.

As mentioned above, we also include the exchange rate of the Thai baht against the US dollar in the system for Malaysia, as a proxy for the contagion effect. As presented in Table 3.1, the one-period lagged Thai exchange rate variable is selected to explain movements in the Malaysian ringgit. The estimated relationship is statistically significant at the 5 per cent level. The coefficient estimate indicates that a depreciation of the Thai baht against the US dollar Granger causes a depreciation of the Malaysian ringgit against the US dollar during the crisis period.

In the case of Thailand, the one-period lagged differential in overnight interest rates is selected as an explanatory variable for the exchange rate. Although the estimated coefficient has a sign consistent with a priori expectations, the associated $t$-statistics is not significant at the 5 per cent level, casting doubts on the test results. In an attempt to improve the estimation, we also first difference the variable, interest rate differential, and repeat the selection procedure. The one-period lagged interest rate differential is again selected in the exchange rate equation, but the coefficient estimate remains insignificant at the 5 per cent level. Consequently, we conclude that, for Thailand, only weak evidence is obtained for the presence of Granger causality from domestic interest rate movements to the currency.

The one-period lagged Malaysian ringgit is also selected as an explanatory variable for movements in the Thai baht, with a $t$-statistics significant at the 5 per cent level. The 
Table 3.1. VAR estimates. $X^{1}$ denotes units of domestic currency per unit of the US dollar, $X^{2}$ denotes differential between domestic and US overnight interest rates, $X^{3}$ denotes differential between domestic and US producer price indexes, and $X^{4}$ denotes another regional exchange rate and $d$ first difference. The zero and nonzero patterned model specifications are determined using the Schwarz criterion.

\begin{tabular}{|c|c|}
\hline Thailand & $\begin{aligned} d \ln X_{t}^{1}= & \underset{(1.30)}{0.0150}+\underset{(3.13)}{0.2118 d \ln X_{t-1}^{1}}-\underset{(2.63)}{0.1401} d \ln X_{t-2}^{1} \\
& -\underset{(1.50)}{0.0053 \ln X_{t-1}^{2}}+\underset{(2.48)}{0.1499} d \ln X_{t-1}^{4} \\
\ln X_{t}^{2}= & \underset{(4.17)}{0.3969}+\underset{(11.31)}{0.6956 \ln X_{t-1}^{2}}+\underset{(2.50)}{0.1530} \ln X_{t-2}^{2} \\
X_{t}^{3}= & \underset{(0.95)}{0.0376}+\underset{(64.56)}{0.9720 X_{t-1}^{3}} \\
d \ln X_{t}^{4}= & \underset{(1.24)}{0.0014}+\underset{(2.06)}{0.1578} \ln X_{t-1}^{1}+\underset{(1.45)}{0.1008 d \ln X_{t-1}^{4}}\end{aligned}$ \\
\hline Malaysia & $\begin{aligned} d \ln X_{t}^{1} & =\underset{(1.22)}{0.0014}+\underset{(1.53)}{0.1049} \ln X_{t-1}^{1}+\underset{(1.98)}{0.1447} \ln X_{t-1}^{4}, \\
X_{t}^{3} & =\underset{(1.61)}{0.0665}+\underset{(56.91)}{0.9553 X_{t-1}^{3}} \\
d \ln X_{t}^{4} & =\underset{(1.01)}{0.0010}+\underset{(2.35)}{0.1398} d \ln X_{t-1}^{1}+\underset{(2.87)}{0.1834 d} \ln X_{t-1}^{4}\end{aligned}$ \\
\hline The Philippines & 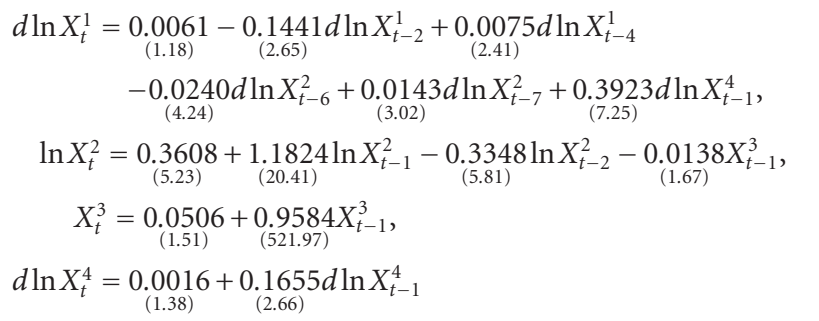 \\
\hline South Korea & 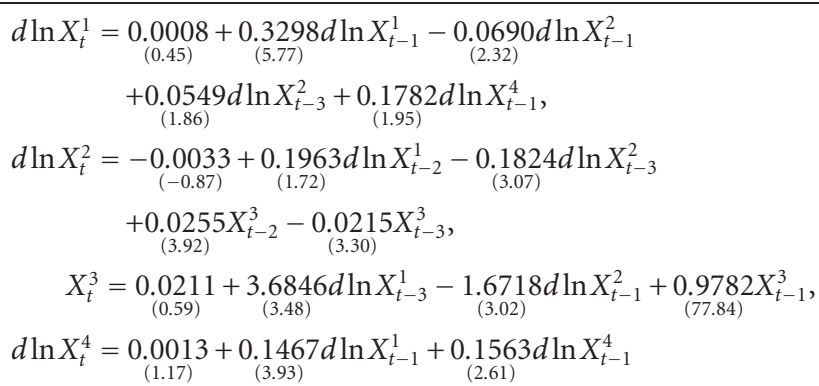 \\
\hline
\end{tabular}

sign of this coefficient estimate is consistent with a priori expectations, reinforcing the significance of currency contagion during the Asian financial crisis.

For the Philippines, the estimated relationship between interest rate differential and movements in the exchange rate appears dynamic. In the equation of exchange rate, the six-period lagged interest rate differential is selected with a negative coefficient, and the seven-period lagged interest rate differential is selected with a positive coefficient. Based on the coefficient estimates, the net effect of a widening of interest rate differential in the Philippines causes an appreciation of the peso against the US dollar. In contrast to the results for Thailand, these coefficient estimates are statistically significant at the 5 per 
cent level, which give strong support for the presence of Granger causality from interest rate movements to the exchange rate. In addition to the effects of interest rate changes, the lagged movements in the Malaysian ringgit significantly influence the peso during the crisis.

For South Korea, the one-period lagged interest rate differential is selected in the equation of exchange rate with a negative coefficient, and the three-period lagged interest rate differential is selected with a positive coefficient. The estimation results indicate that during the Asian financial crisis, higher interest rates adopted by the Korean government help to support the won. The variable, one-period lagged movements in the Malaysian ringgit, is also selected as an explanatory variable for movements in the Korean won. The coefficient estimate indicates that a depreciation of the Malaysian ringgit also results in a decline in the value of the won against the US dollar over the crisis period.

\section{Measurement of linear dependence}

To further understand the effects of interest rate movements on the Asian currencies over the crisis period, we measure the linear dependence in the above VAR systems using the Geweke [7] approach. Two cases of interest are presented in Table 4.1. Testing at the 5 per cent level, 95 per cent confidence intervals are shown parenthetically. In the first case, the linear dependence on the interest rate differential is calculated. In the second case, the linear dependence on the contagion effect is measured. Because of the determined specifications, these measures effectively indicate the linear dependence of the exchange rate on changes in interest rate differential and the contagion effect.

In Table 4.1, the measures indicate that the interest rate effects varied among the Asian exchange rates. In the case of the Philippines, the linear dependence of its peso on interest rate differential is stronger than that for Thailand and South Korea. This effect is also higher than the impact on the currency of the contagion effect.

However, in the cases of Thailand and South Korea, the linear dependence of their exchange rates on changes in interest rate differentials is less significant than the contagion effects. These results indicate that, for these two countries, the exchange rate movements during the Asian financial crisis are more significantly influenced by currency contagion. Despite sharply higher interest rates imposed by the authorities, such a policy response is unable to prevent their currencies from declining against the US dollar.

An important question raised by these results is the appropriateness of using a high interest rate policy to defend the currency, especially in the presence of significant currency contagion. There are economic consequences associated with sharply higher interest rates. For example, sharply higher interest rates, if sustained, will lead to a marked slowdown in economic activity.

To further demonstrate the impact of changes in interest rate differentials and currency contagion on movements in the Asian exchange rates during the crisis period, we also examine the forecasting performance of our models. To undertake this exercise, we divide the sample into two periods. The first period consists of data from 1 July 1997 to 18 June 1998 and the second period consists of data from 19 June to 1 July 1998 . We use data from the first period to reestimate the VAR specification for each country and then produce the 
Table 4.1. Measurement of linear dependence. Confidence intervals in brackets. Nonzero measurement indicates the existence of Granger causality.

\begin{tabular}{|c|c|c|c|c|c|}
\hline \multirow[b]{2}{*}{ Thailand } & \multicolumn{2}{|c|}{$X_{t}=\left[\begin{array}{lll}x_{t}^{1} & x_{t}^{3} & x_{t}^{4}\end{array}\right] Y_{t}=\left[x_{t}^{2}\right]$} & \multicolumn{3}{|c|}{$X_{t}=\left[\begin{array}{lll}x_{t}^{1} & x_{t}^{2} & x_{t}^{3}\end{array}\right] Y_{t}=\left[x_{t}^{4}\right]$} \\
\hline & 0.007 & {$\left[\begin{array}{ll}-0.002 & 0.015\end{array}\right]$} & 0.032 & {$[0.002$} & $0.653]$ \\
\hline Malaysia & - & Not available & 0.025 & {$[0.001$} & $0.580]$ \\
\hline The Philippines & 0.176 & {$\left[\begin{array}{ll}0.002 & 0.345\end{array}\right]$} & 0.059 & {$[0.002$} & $0.131]$ \\
\hline South Korea & 0.013 & {$\left[\begin{array}{ll}0.001 & 0.035\end{array}\right]$} & 0.045 & {$[0.005$} & 0.094] \\
\hline
\end{tabular}

Table 4.2. Forecasting performance.

\begin{tabular}{l|c|c|c}
\hline & AR & $\begin{array}{c}\text { VAR including interest rate } \\
\text { and currency contagion }\end{array}$ & Improvement \\
\hline Thailand & $1.53 \%$ & $1.49 \%$ & $2.85 \%$ \\
Malaysia & $2.44 \%$ & $2.33 \%$ & $4.52 \%$ \\
The Philippines & $1.43 \%$ & $0.75 \%$ & $47.3 \%$ \\
South Korea & $3.18 \%$ & $2.46 \%$ & $22.5 \%$ \\
\hline
\end{tabular}

forecasts for the second period. To examine the forecasting performance, we calculate the root mean squared error (RMSE) for the respective exchange rate over the forecast period, expressed as the percentage of the sample mean over the forecast period (see Table 4.2).

For the purpose of comparison, we also construct a set of univariate autoregressive (AR) systems for the four Asian exchange rates using the Brailsford et al. procedure. Similarly, these AR systems are first estimated using observations from the first period. Forecasts for the second period are then produced and the RMSEs are calculated.

Table 4.2 presents the improvement in forecasting performance of our models. The results indicate that interest rate movements and currency contagion are two important factors in the determination of Asian exchange rates during the crisis period. Consistent with the estimation results presented in Table 3.1, the improvement in forecasting performance is particularly significant for the Philippines and South Korea.

\section{Summary}

In this paper, we have reexamined the effects on Asian exchange rates of higher interest rates during the Asian financial crisis. In contrast to most previous studies, we find that higher interest rates provided support for many Asian exchange rates during the crisis. This finding is consistent with the traditional view about this relationship. We find no evidence to support the revisionist view, in which sharply higher interest rates are argued to lead to a weaker exchange rate during financial crises.

Currency contagion is found to be significant in the Asian financial crisis. In the cases of Thailand and South Korea, the contagion effects on their currencies are deemed to be more significant than the impacts of sharply higher interest rates. This finding raises questions about the appropriateness of using a high interest rate policy to defend an exchange rate, especially in the presence of contagion. 


\section{References}

[1] T. Brailsford, J. H. W. Penm, and R. D. Terrell, The adjustment of the Yule-Walker relations in VAR modelling: the impact of the Euro on the Hong Kong stock market, Multinational Finance Journal 5 (2001), no. 1, 35-58.

[2] G. Caporale, A. Cipollini, and P. Demetriades, Monetary policy and the exchange rate during the Asian crisis: identification through heteroscedasticity, working paper, Department of Economics, University of Leicester, Leicester, 2000.

[3] I. Choi and D. Park, Causal relation between interest and exchange rates in the Asian currency crisis, working paper, Kookmin University, Seoul, 2000.

[4] R. Dekle, C. Hsiao, and S. Wang, High interest rates and exchange rate stabilization in Korea, Malaysia, and Thailand: an empirical investigation of the traditional and revisionist views, Review of International Economics 10 (2002), no. 1, 64-78.

[5] D. A. Dickey and W. A. Fuller, Distribution of the estimators for autoregressive time series with a unit root, Journal of the American Statistical Association 74 (1979), no. 366, part 1, 427-431.

[6] M. Feldstein, Refocusing the IMF, Foreign Affairs 77 (1998), no. 2, 20-33.

[7] J. Geweke, Measurement of linear dependence and feedback between multiple time series, Journal of the American Statistical Association 77 (1982), no. 378, 304-324.

[8] I. Goldfajn and T. Baig, Monetary policy in the aftermath of currency crises: the case of Asia, working paper, International Monetary Fund, Washington, DC, 1998.

[9] D. Gould and S. Kamin, The impact of monetary policy on exchange rate during financial crises, working paper, Board of Governors of the Federal Reserve System, Washington, DC, 1999.

[10] C. Hsiao, Autoregressive modelling of Canadian money and income data, Journal of the American Statistical Association 74 (1979), no. 367, 553-560.

[11] International Monetary Fund, The role of monetary policy in responding to currency crises, World Economic Outlook, , Washington, DC, 1998.

[12] G. Kaminsky and S. Schmukler, The relationship between interest rates and exchange rates in six Asian countries, working paper, The World Bank, Washington, DC, 1998.

[13] J. Nagayasu, Currency crisis and contagion: evidence from exchange rates and sectoral stock indices of the Philippines and Thailand, Journal of Asian Economics 12 (2001), no. 4, 529-546.

[14] Y. C. Park, C.-S. Chung, and Y. Wang, Exchange rate policies in Korea: has exchange rate volatility increased after the crisis?, working paper, Korean Institute for Economic Policy, East Asian Bureau of Economic Research, 1999.

[15] J. H. W. Penm and R. D. Terrell, Multivariate subset autoregressive modelling with zero constraints for detecting overall causality, Journal of Econometrics 24 (1984), no. 3, 311-330.

[16] J. H. Stock and M. W. Watson, Testing for common trends, Journal of the American Statistical Association 83 (1988), no. 404, 1097-1107.

[17] A. Zellner, An efficient method of estimating seemingly unrelated regressions and tests for aggregation bias, Journal of the American Statistical Association 57 (1962), no. 298, 348-368.

Tim Brailsford: UQ Business School, The University of Queensland, Brisbane QLD 4072, Australia E-mail address: t.brailsford@business.uq.edu.au

Jack H.W. Penm: School of Finance \& Applied Statistics, College of Business and Economics, The Australian National University, Canberra ACT 0200, Australia

E-mail address: jack.penm@anu.edu.au

Chin Diew Lai: Institute of Information Sciences and Technology, Massey University,

Palmerston North, New Zealand

E-mail address: c.lai@massey.ac.nz 


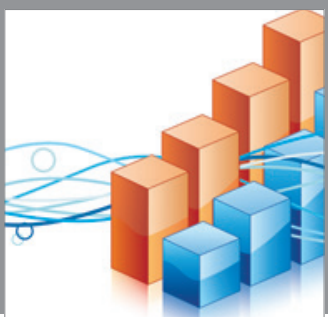

Advances in

Operations Research

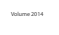

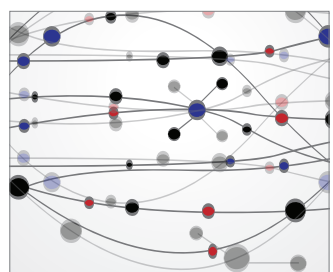

\section{The Scientific} World Journal
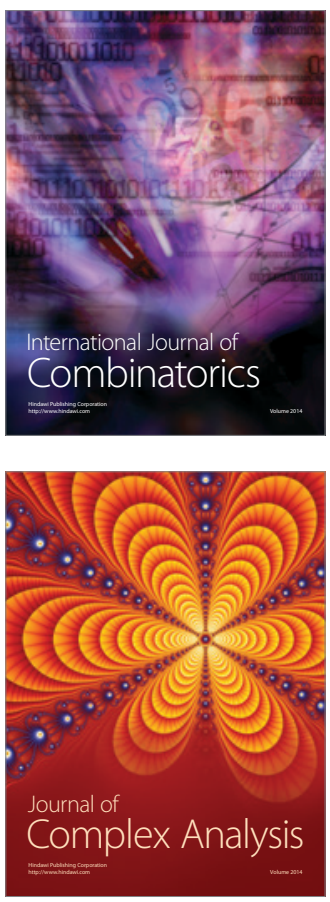

International Journal of

Mathematics and

Mathematical

Sciences
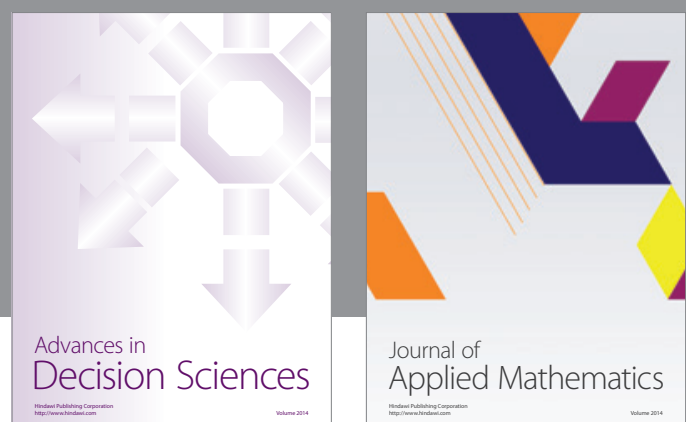

Journal of

Applied Mathematics
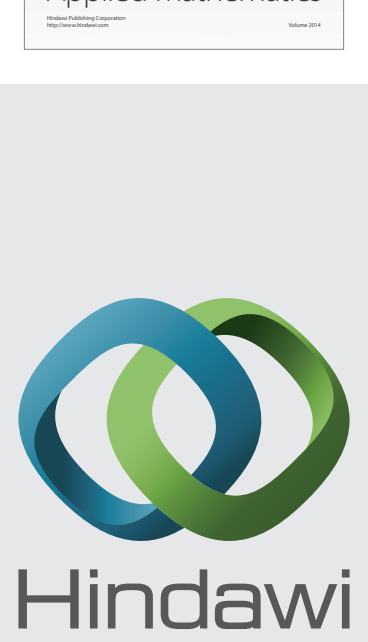

Submit your manuscripts at http://www.hindawi.com
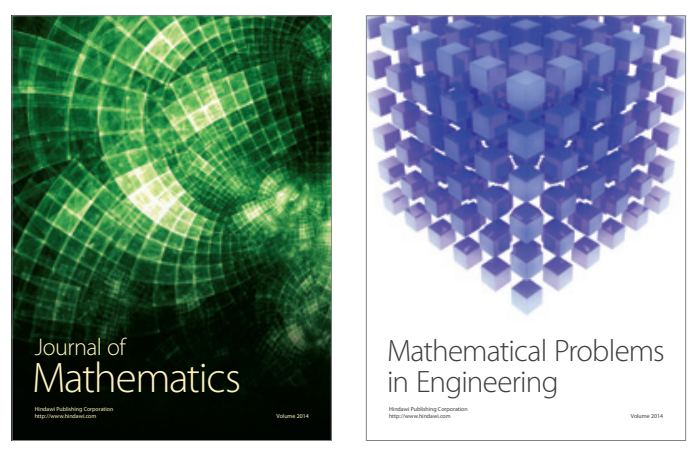

Mathematical Problems in Engineering
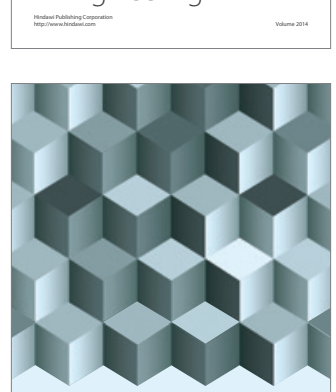

Journal of

Function Spaces
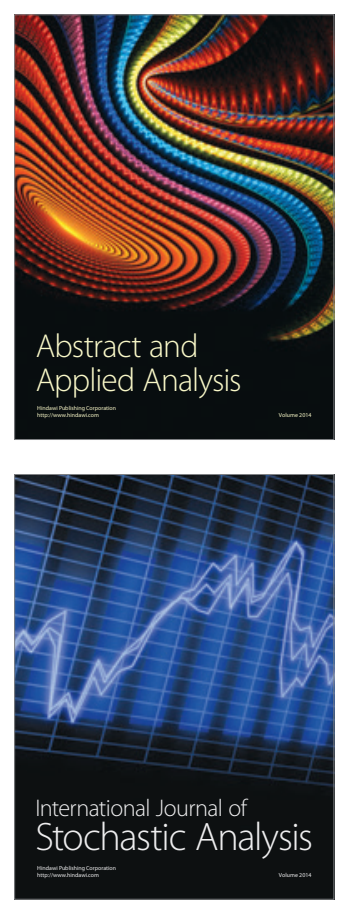

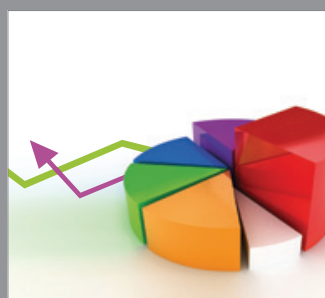

ournal of

Probability and Statistics

Promensencen
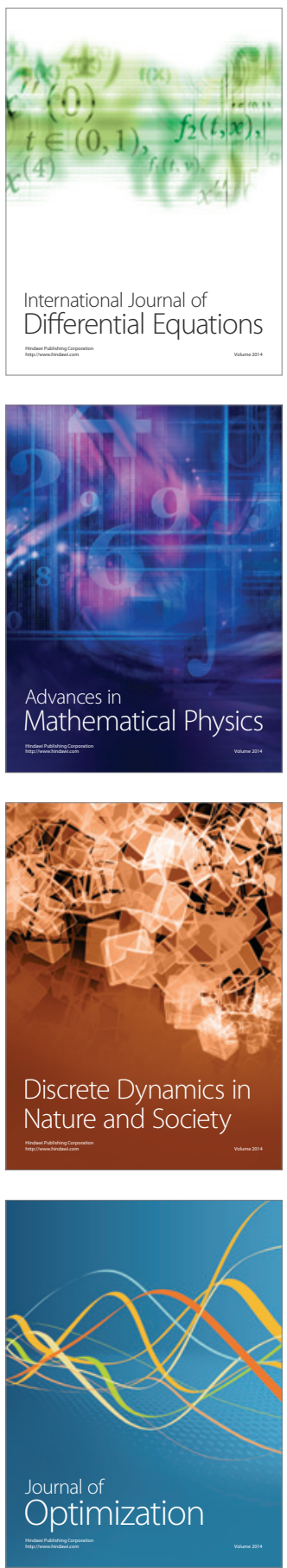